PROCEEDINGS OF THE WORLD CONFERENCE ON OZONE THERAPY IN MEDICINE, DENTISTRY AND VETERINARY. ANCONA (ITALY). SEPTEMBER 22nd - 23rd - 24th, 2017

\title{
Detection of circulating tumor cells and intervention with systemic ozone therapy hematic-route [abstract]
}

\section{Yasuhiro Shimpuku}

Imperio Clinic, Miyazaki, Japan.

\section{ABSTRACT}

\section{OPEN ACCESS}

\section{Citation}

Shimpuku Y. Detection of circulating tumor cells and intervention with systemic ozone therapy hematic-route [abstract]. Proceedings of The World Conference on Ozone Therapy in Medicine, Dentistry and Veterinary. Ancona (Italy). September 22nd - 23rd - 24th , 2017. J Ozone Ther. 2019;3(4):60. doi: 10.7203/ jo3t.3.4.2019.15542

Academic Editor Jose Baeza-Noci,

School of Medicine, Valencia University, SPAIN

\section{Editor}

World Federation of Ozone Therapy, Bolgna, ITALY

\section{Received}

June 17, 2019

\section{Accepted}

December 08, 2019

Published

December 30, 2019

\section{Intellectual Property}

Yasuhiro Shimpuku.

This is an open access article distributed under the terms of the Creative Commons Attribution License (CC BY 4.0), which permits unrestricted use, distribution, and reproduction in any medium, provided the original author and source are credited.

\section{Author Information} imperioclinic@yahoo.co.jp
Background. Circulating tumor cells (CTC) test have been used for detecting cancer cells in circulating blood of cancer patients and it can suggest treatment methods against their cancer.

When it will be used for very early stage cancer detection even if tumor can't be found by imaging tests like CT or PET, systemic ozone treatment hematic (SOT-h) might be a strong candidate for cancer elimination.

Case Presentation. 59 years old male patient who is suffering from moderate periodontal disease (AAP grade III) and severe T2DM was checked with dental examinations and medical examinations with CTC test. The data showed that he had $12.1 \mathrm{CTCs} / \mathrm{mL}+/-0.3$ that is more than 2 times from cut off point $5.0 \mathrm{CTCs} / \mathrm{mL}$. Several anti-cancer treatments were also suggested. No tumor was detected by PET. Since Nrf 2 activation and heat shock protein stimulation are recommended for treatment, SOT-h was applied in order to reduce CTCs in Imperio clinic, Japan. Because SOT-h have been shown it can activate these transcription factors and stress proteins. The patient had SOT-h for 2 times a week during 13 weeks, and then he had it for 1 time a week during another 28 weeks. The results showed that significant decrease of CTCs as $10.7 / \mathrm{mL}$ at 13 weeks and 6.9/ $\mathrm{mL}$ at 41 weeks respectively. The patient didn't have chemotherapy, but he had several supplements including ascorbic acid and curcumin in accordance with the results of CTC test. Anti-cancer effect by these natural substances can't ignore. Because they might act for same epigenetic regulation of gene expression as SOT-h.

Conclusion. This case shows the possibility of reducing the number of circulating tumor cells by SOT-h on very early cancer stage.

\section{References}

1. Papasotiriou, I, et al. Detection of circulating tumor cells in patients with breast, prostate, pancreatic, colon and melanoma cancer: a blinded comparative study using healthy donors. J Cancer Ther. 2015;6:543-553. doi:10.4236/jct.2015.67059.

2. Somma F, Castagnola R, Bollino D, Marigo L. Oral inflammatory process and general health. Part 2: How does the periapical inflammatory process compromise general health? Eur Rev Med Pharmacol Sci. $2011 ; 15(1): 35-51$. 